\title{
Research Paper: The Relationship Between Dispositional Mindfulness, Temperament and Character Dimensions of Personality and Identity Styles
}

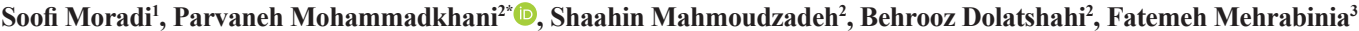

1. Department of Clinical and Health Psychology, Faculty of Education and Psychology, Shahid Beheshti University, Tehran, Iran

2. Department of Clinical Psychology, University of Social Welfare and Rehabilitation Sciences, Tehran, Iran.

3. Department of Clinical Psychology, Faculty of Humanities, Sari Branch, Islamic Azad University, Sari, Iran.



dteation: Moradi, S., Mohammadkhani, P., Mahmoudzadeh, Sh., Dolatshahi, B., \& Mehrabinia, F. (2018). The Relationship Between Dispositional Mindfulness, Temperament and Character Dimensions of Personality and Identity Styles. Journal of Practice in Clinical Psychology, 6(2), 93-100. https://doi.org/10.29252/NIRP.JPCP.6.2.93

doi : https://doi.org/10.29252/NIRP.JPCP.6.2.93

Article info:

Received: 27 Apr. 2017

Accepted: 30 Oct. 2017
Keywords:

Mindfulness, Temperament,

Character, Identity crisis

\section{ABSTRACT}

Objective: This study was conducted to examine the relationships between dispositional mindfulness, temperament, personality traits, and identity styles and to determine the predictive power of dispositional mindfulness, temperament, personality traits in identity styles.

Methods: 223 students (120 females and 103 males) from the universities in Tehran were selected as the sample. The data were gathered using the Temperament and Character Inventory, the Mindful Attention Awareness Scale, and the Identity Style Inventory.

Results: Dispositional mindfulness was significantly correlated with identity styles and identity commitment. There were also significant relationships between mindfulness and temperament dimensions and character dimensions $(-0.32$ to $0.38, \mathrm{P}<0.01)$. Regression analysis indicated that three personality dimensions, i.e., self-directedness, self-transcendence, novelty seeking and dispositional mindfulness predict $35 \%$ of the variance of identity commitment; and dispositional mindfulness, self-transcendence, cooperativeness and novelty seeking predict $26 \%$ of the variance of normative identity style.

Conclusion: The findings of this study indicate that mindfulness and the psychobiological aspects of personality may have a significant role in the process of identity achievement. Also, the biological aspects of personality may have a significant role in dispositional mindfulness.

\section{Introduction}

I $\mathrm{n}$ the modern approaches, identity achievement is considered as a process starting from childhood and it is believed that the student years (18-25 years) are important for identity development (Tanner, Arnett, \& Furlong, 2009; Blimling, 2003). Berzonsky (1990) identifies three iden- tity styles - informational, normative and diffuse-avoidant. In general, these styles are regarded as cognitive-social styles. They refer to information processing methods and approaches in terms of identity, personal decisionmaking, especially when dealing with identity-related issues. An informational identity style has been found to be positively related to self-reflection, problem-focused coping efforts, rational epistemic levels, and a need for

* Corresponding Author:

Parvaneh Mohammadkhani, PhD

Address: Department of Clinical Psychology, University of Social Welfare and Rehabilitation Sciences, Tehran, Iran.

Tel: +98 (935) 6373896

E-mail:parmohamir@yahoo.com 
knowing cognitive complexity, purposeful decisionmaking, responsibility, acceptance, and successful identity development (Berzonsky \& Kuk, 2005). In their decision-makings and dealings with identity-related issues, individuals with a normative identity style conform to expectations and orders of important figures and reference groups, accept and internalize values and beliefs automatically without conscious evaluation, have a low tolerance for facing new and ambiguous situations, and show a powerful need for structure and closure (Berzonsky \& Kuk, 2005; Berzonsky \& Ferrari, 1996). Individuals with a diffuse-avoidant identity style hesitate and avoid identity-related issues and decision-making as much as possible. In decision-making situations, and before making a decision, such individuals have low confidence in their cognitive abilities, are afraid and anxious, and use inappropriate decision-making strategies, like avoidance and making excuses (Berzonsky \& Ferrari, 1996).

Some researchers emphasize the importance of the effects of these factors on identity development (e.g. Duriez \& Soenens, 2006; Dollinger, 1995). Duriez and Soenens (2006) found positive relationships between identity styles and Big Five personality traits. Cloninger, a personality theorist, believes that an individual's personality forms under the influence of temperament and character traits. He presents a psychobiological model of personality that includes four temperaments (novelty seeking, harm avoidance, reward dependence, and persistence) and three characters (self-directedness, cooperativeness and self-transcendence) dimensions. The temperament dimensions depend on individual genetics, and appear in early development; the character dimensions are related to individual differences in terms of learning mechanisms, self-perception, goals and values formed during development stages of life (De Fruyt, Wiele \& Van Heeringen, 2000).

It appears that biological aspects of personality along with character considerably contribute to the formation of identity styles. Given that previous studies have not paid enough attention to this subject, the present study aims to examine biological aspects of personality using the Temperament and Character Inventory (TCI-125). Taking biological aspects of personality into account, we can further understand adolescent's identity formation process, and able to explain identity crisis during adolescence. Many studies have investigated mindfulness as a personality trait, or a predictive factor in personality (e.g. Brown \& Ryan, 2003; Latzman \& Masuda, 2013; Hamill, Pickett, Amsbaugh \& Aho, 2015; Bao, Xue \& Kong, 2015). Mindfulness is defined as paying attention to the present moment, intentionally, in a particular way, and in a non-judgmental manner (Kabat-Zinn, 2003). Therefore, it seems it would be useful to measure mindfulness as a central variable in clinical interventions, or as a moderator, or even as a personality trait (Walach, Buchheld, Buttenmüller, Kleinknecht \& Schmidt, 2006). We can't explain the relationship of dispositional mindfulness with different emotions and other mental health scales without considering social factors, or the joint variance of general personality traits, like neuroticism and extraversion and their effect on psychological wellbeing (Brown \& Ryan, 2003; Giluk, 2009; Latzman \& Masuda, 2013; Tucker et al., 2014); These findings indicate that we can look at the process of identity achievement from different perspectives. Also, mindfulness can have positive effects on identity development in young people; for example, Verni (2007) suggests that mindfulness should be studied as an effective factor in identity achievement, because it can help adolescents in coping with identity achievement in stressful situation, self-concept formation, and selecting personal values and goals.

The present study aims to clarify the process of identity achievement and help in finding a better understanding of the process. Moreover, due to personality traits effects on the identity achievement process, and a lack of studies on the biological and character aspects of dispositional mindfulness, this study investigates the relationships of dispositional mindfulness with biological and character personality traits. Another goal of the study is to explore the predictive role of dispositional mindfulness along with the biological and character aspects of personality in identity styles.

\section{Methods}

Cross-sectional design is used for this study. The population includes Tehran universities' students in February 2013. The sample consists of 223 students selected using a multistage cluster sampling method. The students were randomly chosen from five universities in TehranShahid Beheshti University, Tehran University, Allameh Tabatabaei University, the University of Social Welfare and Rehabilitation Sciences, and Kharazmi University. In the first step of sampling, four dormitories were randomly selected. Then, dormitory floors were randomly selected as the final cluster, and questionnaires were distributed among the students on each floor. Students were given an hour to complete the questionnaires. The inclusion criteria were an age group of 18-25 years and informed consent for participation in the research. The exclusion criteria comprised incomplete or distorted answers. A total of 238 questionnaires were collected. Fifteen questionnaires were rejected because of incomplete 
or distorted responses. Finally, 223 questionnaires were used for data analysis. In order to maintain anonymity and confidentiality, participants' real names or other personal information were excluded. Most importantly, participants had the option to quit the study at any stage, even after completing the questionnaires. Measures used in this study were Mindful Attention Awareness Scale (MAAS), Temperament and Character Inventory (TCI125), and Identity Style Inventory (ISI-6G).

The Mindful Attention Awareness Scale (MAAS) was used to assess dispositional mindfulness. The 15-items scale, developed by Brown and Ryan, assesses the level of consciousness and level of attention to every day events and experiences (Brown \& Ryan, 2003). The MAAS is a 6-point Likert-type scale ranging from $1=$ almost always to $6=$ almost never. It gives a total score from 15 to 90 ; higher scores indicate greater mindfulness. The items of the questionnaire had high internal consistency in student and adult samples (Cronbach's alphas of 0.82 and 0.87 , respectively). The MAAS has positive correlations with openness to experience, emotional intelligence, and well-being; and negative correlation with rumination and social anxiety; and these correlations are evidences for the convergent and discriminant validity of the scale. The Buddhist trainees had significantly scored higher on the MAAS than a matched control group (Baer, Walsh, \& Lykins, 2009). Previous studies have also found the concurrent and discriminant validity of the MAAS in Iranian samples. For example, Ghorbani, Watson \& Weathington (2009) found Cronbach's alpha of 0.81 for this scale in an Iranian sample; Cronbach's alpha was 0.77 in the present study.

The Temperament and Character Inventory (TCI-125) was developed by Cloninger, Przybeck, Svrakic, \& Wetzel (1994) to assess personality traits. This inventory has four temperament dimensions - novelty seeking, harm avoidance, reward dependence, and persistence; and three character dimensions- self-directedness, cooperativeness, and self-transcendence. The items are scored yes $=1$ and no $=0$. The TCI- 125 has good validity and reliability values. The factor structures of the character and temperament subscales are similar to the original factors. In addition, test-retest reliability estimates (1-2 month interval) from 0.72 to 0.84 have been found for the temperament scales, and from 0.72 to 0.78 for the character subscales (Takeuchi et al., 2011). In Iran, Cronbach's alphas greater than 0.80 has been reported for all the dimensions of TCI-125, and there is no significant correlation between its dimensions; a finding which indicates that the dimensions are independent of each other (Naseh \& Kaviani 2005). In the present study, the
Cronbach's alpha was 0.61 for novelty seeking, 0.72 for harm avoidance, 0.45 for reward dependence, 0.60 for persistence, 0.78 for self-directedness, 0.71 for cooperativeness; and 0.75 for self-transcendence.

The Identity Style Inventory (ISI-6G) was developed by Berzonsky (1990) to evaluate identity styles. The original questionnaire has 40 items, and assesses three identity styles (informational, normative, and diffuse-avoidant), and an identity dimension, namely identity commitment (Berzonsky, 2004). The ISI-6G is a 5-point Likert-type scale ranging from totally disagree $=1$ to totally agree $=5$. White, Wampler, \& Winn (1998) reported Cronbach's alphas of 0.70 for informational style, 0.68 for normative style and 0.70 for diffuse-avoidant style (as cited in Vaziri, Kashani, Jamshidifar \& Vaziri, 2014). In Iranian samples, the Cronbach's alphas for the informational style, normative style, diffuse-avoidant style and commitment dimension were reported as $0.83,0.72,0.56$ and 0.84 , respectively (Vaziri et al., 2014). In the present study, the Cronbach's alphas of informational style, normative style, diffuse-avoidant style and commitment dimension were calculated as $0.63,0.56,0.54$ and 0.59 , respectively. The participants were informed about the objectives and the procedure of the study, and they were allowed to quit the study at any time. In order to ensure confidentiality, the real names of participants and their other personal information were not included in the study. The questionnaires were given to the students who agreed to participate in the study and met the qualifications. The data were gathered from University dormitories.

\section{Results}

An examination of scatter plots confirmed the assumption of linearity between the independent variables and dependent variables. An inspection of skewness, kurtosis, and histograms, showed the normality of all variables. A visual inspection of Q-Q plot showed a multivariate normal distribution for the dependent variables. The Tolerance index (TI) ranging from 0.6 to 1 ; and the Variance Inflation Factor (VIF) ranging from 1 to 1.63 , supported the absence of multicollinearity between the variables. The Durbin-Watson test showed the absence of auto-correlation. The values of Durbin-Watson test were as follows - normative identity style $(\mathrm{d}=1.85)$, informational identities style $(\mathrm{d}=1.90)$, diffuse-avoidant style $(d=1.87)$ and commitment $(d=2.02)$. The homoscedasticity and normality of residuals were confirmed using an inspection of residual Q-Q plots, skewness, and kurtosis.

Demographic information of the participants is presented in Table 1. The Pearson correlation coefficient was 
Table 1. Demographic information of the participants

\begin{tabular}{|c|c|c|c|}
\hline & Variables & $n$ & $\%$ \\
\hline Gender & $\begin{array}{c}\text { Male } \\
\text { Female }\end{array}$ & $\begin{array}{l}103 \\
120\end{array}$ & $\begin{array}{l}46 \\
54\end{array}$ \\
\hline Age & $\begin{array}{l}18-21 \\
22-25\end{array}$ & $\begin{array}{c}95 \\
128\end{array}$ & $\begin{array}{l}42.6 \\
57.4\end{array}$ \\
\hline Education & $\begin{array}{l}\text { BSc. student } \\
\text { MA student }\end{array}$ & $\begin{array}{c}171 \\
52\end{array}$ & $\begin{array}{l}77 \\
23\end{array}$ \\
\hline
\end{tabular}

used to examine the relationship between temperament and personality dimensions, identity styles, and mindfulness. The stepwise regression analysis method was used to determine the role of mindfulness and personality characteristics in identity styles. We predicted four models based on the identity styles. Given the higher prediction power of the normative and informative identity styles, these models are presented in Tables 3 and 4.

The findings show significant correlations between dispositional mindfulness and informational identity style $(\mathrm{r}=0.15, \mathrm{P}<0.05)$, normative identity style $(\mathrm{r}=0.35$, $\mathrm{P}<0.01)$, diffuse-avoidant identity style $(\mathrm{r}=-0.31, \mathrm{P}<0.01)$, and identity commitment dimension $(\mathrm{r}=0.38, \mathrm{P}<0.01)$. There are also significant correlations between mindfulness and novelty seeking $(\mathrm{r}=-0.32, \mathrm{P}<0.01)$, harm avoidance $(\mathrm{r}=-0.16, \mathrm{P}<0.05)$, reward dependence $(\mathrm{r}=0.14$, $\mathrm{P}<0.05)$, self-directedness $(\mathrm{r}=0.45, \mathrm{P}<0.01)$, and cooperativeness $(\mathrm{r}=0.36, \mathrm{P}<0.01)$. There are also significant relationships between informational identity style and all personality dimensions except reward dependence. Normative identity style is significantly correlated with all personality dimensions except harm avoidance. Diffuseavoidant identity style has significant correlations with all personality dimensions except harm avoidance, reward dependence, and self-transcendence. Identity commitment is significantly related to all personality dimensions except reward dependence (Table 2).

\section{Stepwise regression analyses}

As you can see in Table 3, in the first step, mindfulness accounts for $12 \%$ of the variance; in the second step, mindfulness and self-transcendence account for $22 \%$ of the variance; in the third, mindfulness, selftranscendence, and cooperativeness account for $26 \%$ of the variance; and in the fourth step, mindfulness $(\beta=0.27$; $\mathrm{P}<0.001)$, self-transcendence $(\beta=0.29 ; \mathrm{P}<0.001)$, cooperativeness $(\beta=0.17 ; \mathrm{P}<0.01)$, and novelty seeking $(\beta=0.13$; $\mathrm{P}<0.05$ ) account for $27 \%$ of the variance.

According to Table 4, the results of stepwise regression analysis for trait mindfulness and personality traits predicting the identity styles indicate that in the final step, $35 \%$ of the variance of identity commitment is predicted by self-directness $(\beta=0.29 ; \mathrm{P}<0.001)$, self-transcendence ( $\beta=0.27 ; \mathrm{P}<0.001)$, novelty seeking $(\beta=-0.20 ; \mathrm{P}<0.001)$, and mindfulness $(\beta=0.20 ; \mathrm{P}<0.001)$. Regression analysis

Table 2. Correlations between mindfulness, identity styles, and personality dimensions

\begin{tabular}{|c|c|c|c|c|c|c|}
\hline Identity Style & $M(S D)$ & $\begin{array}{c}\text { Mindfulness } \\
66.6(8.8)\end{array}$ & $\begin{array}{c}\text { Informational } \\
38.7(5.3)\end{array}$ & $\begin{array}{c}\text { Normative } \\
31.4(4.8)\end{array}$ & $\begin{array}{c}\text { Diffuse-Avoidant } \\
26(5)\end{array}$ & $\begin{array}{c}\text { Commitment } \\
35.9(5.6)\end{array}$ \\
\hline Mindfulness & $66.6(8.8)$ & 1.00 & $0.15^{*}$ & $0.35^{* *}$ & $-0.31^{* *}$ & $0.38^{* *}$ \\
\hline Novelty seeking & $9(3.3)$ & $-0.32^{* *}$ & $-0.26^{* *}$ & $-0.25^{* *}$ & $0.32^{* *}$ & -0.36 \\
\hline Harm avoidance & $8.3(3.9)$ & $-0.16^{*}$ & $-0.20^{* *}$ & -0.12 & 0.09 & $-0.29^{* *}$ \\
\hline Reward dependence & $8.5(2.5)$ & $0.14^{*}$ & 0.06 & $0.22^{* *}$ & -0.01 & 0.04 \\
\hline Persistence & $2.8(1.5)$ & 0.03 & $0.21^{* *}$ & $0.17^{*}$ & $-0.17^{*}$ & $0.22^{* *}$ \\
\hline Self-directedness & $14.4(4.7)$ & $0.45^{* *}$ & $0.23^{* *}$ & $0.27^{* *}$ & $-0.37^{* *}$ & $0.46^{* *}$ \\
\hline Cooperativeness & $18(3.7)$ & $0.36^{* *}$ & $0.25^{* *}$ & $0.35^{* *}$ & $-0.28^{* *}$ & $0.25^{* *}$ \\
\hline Self-transcendence & $9.4(3.3)$ & -0.06 & $0.23^{* *}$ & $0.29^{* *}$ & 0.01 & $0.24^{* *}$ \\
\hline
\end{tabular}


Table 3. Summary of stepwise regression analysis for variables predicting normative identity style ( $\mathrm{N}=223)$

\begin{tabular}{|c|c|c|c|c|c|}
\hline & R Square & $\mathbf{F}$ & $\mathbf{T}$ & $\beta$ & $\mathbf{P}$ \\
\hline Step 1 & 0.125 & 29.835 & & & \\
\hline Normative & & & 7.639 & & 0.000 \\
\hline Mindfulness & & & 5.462 & 0.354 & 0.000 \\
\hline Step 2 & 0.228 & 30.501 & & & \\
\hline Normative & & & 5.151 & & \\
\hline Mindfulness & & & 6.206 & 0.380 & 0.000 \\
\hline Self-transcendence & & & 5.233 & 0.321 & 0.000 \\
\hline Step 3 & 0.262 & 24.318 & & & \\
\hline Normative & & & 4.576 & & \\
\hline Mindfulness & & & 4.802 & 0.309 & . 000 \\
\hline Self-transcendence & & & 4.584 & 0.282 & 0.000 \\
\hline Cooperativeness & & & 3.076 & 0.200 & 0.000 \\
\hline Step 4 & 0.278 & 19.745 & & & \\
\hline Normative & & & 5.050 & & \\
\hline Mindfulness & & & 4.168 & 0.274 & 0.000 \\
\hline Self-transcendence & & & 4.748 & 0.290 & 0.000 \\
\hline Cooperativeness & & & 2.689 & 0.176 & 0.008 \\
\hline Novelty seeking & & & -2.171 & -0.138 & 0.031 \\
\hline
\end{tabular}

also showed that novelty seeking, self-transcendence, and harm avoidance accounted for $15 \%$ of the variance of informational identity style; and dispositional mindfulness, self-directedness, and novelty seeking accounted for $19 \%$ of the variance of diffuse-avoidant identity style.

\section{Discussion}

The finding of this study revealed negative relationships between mindfulness and two temperament dimensions - harm avoidance and novelty seeking; and positive relationships between mindfulness and two character personality dimensions - cooperativeness and self-directedness. These findings are consistent with the studies of Giluk (2009), Barnhofer, Duggan, \& Griffith (2011), Sauer, Walach, \& Kohls (2011), Thompson \& Waltz (2007), and Manfredi et al. (2011). In a meta-analysis study, Giluk (2009) found significant relationships between mindfulness and the Big Five personality traits. For example, mindfulness was negatively correlated with neuroticism, and positively correlated with responsibility.

Barnhofer et al. (2011) found the mediating role of dispositional mindfulness in the relationship between neu- roticism and depression symptoms. According to this finding, dispositional mindfulness may act as a protective factor against the effects of negative emotions which are exaggerated by neuroticism. The present study also found that harm avoidance was highly overlapped with neuroticism, and the negative relationship with dispositional mindfulness. The finding of Sauer et al. (2011) related to the mediating role of behavioral inhibition system in the relationship between dispositional mindfulness and wellbeing, indicates the effects of temperament dimensions on mindfulness. This finding is consistent with our findings regarding the significant relationships between mindfulness and two temperament dimensions - novelty seeking and responsibility. In another previous study, it was found that mindfulness was positively correlated with agreeableness and conscientiousness; and negatively correlated with neuroticism (Thompson \& Waltz, 2007).

Harm avoidance leads to an increase in rumination and worrying (Manfredi et al., 2011). One of the mechanisms of mindfulness, which improves well-being, is a decrease in rumination. Therefore, higher levels of harm avoidance are related to low mindfulness, and this leads to an increase in rumination. This indicates a negative 
Table 4. Summary of stepwise regression analysis for variables predicting commitment $(\mathrm{N}=223)$

\begin{tabular}{|c|c|c|c|c|c|}
\hline & R Square & $\mathbf{F}$ & $\mathbf{T}$ & $\beta$ & $\mathbf{P}$ \\
\hline Step 1 & 0.212 & 57.052 & & & \\
\hline Commitment & & & 25.321 & 0.460 & 0.000 \\
\hline Self-directness & & & 7.553 & & 0.000 \\
\hline Step 2 & 0.278 & 40.533 & & & \\
\hline Commitment & & & 16.639 & & 0.000 \\
\hline Self-directness & & & 7.887 & 0.462 & 0.000 \\
\hline Self-transcendence & & & 4.374 & 0.256 & 0.000 \\
\hline Step 3 & 0.324 & 33.570 & & & \\
\hline Commitment & & & 15.065 & & 0.000 \\
\hline Self-directness & & & 5.953 & 0.368 & 0.000 \\
\hline Self-transcendence & & & 4.718 & 0.268 & 0.000 \\
\hline Novelty seeking & & & -3.804 & -0.236 & 0.000 \\
\hline Step 4 & 0.355 & 28.716 & & & \\
\hline Commitment & & & 6.794 & & 0.000 \\
\hline Self-directness & & & 4.441 & 0.290 & 0.000 \\
\hline Self-transcendence & & & 4.984 & 0.278 & 0.001 \\
\hline Novelty seeking & & & -3.256 & -0.201 & 0.002 \\
\hline Mindfulness & & & 3.145 & 0.200 & \\
\hline
\end{tabular}

relationship between mindfulness and harm avoidance, a consistent relationship with the findings of the present study. Due to the strong correlation between mindfulness and novelty seeking, and the significant relationships between mindfulness and two other temperament dimensions - harm avoidance and reward dependence and because these dimensions are genetically coded, and environmental factors have little effect on their stability or instability, we can assume that mindfulness has underlying biological factors. These findings may indicate a need for a new and more appropriate formulation of mindfulness. There was no significant relationship between mindfulness and self-transcendence, a finding which indicates that the judgmental qualities of self-transcendence may have an impact on dispositional mindfulness scores. It also suggests that the MAAS doesn't assess spiritual experiences, but rather assesses present moment awareness and attention. It may, therefore, have implied that attending to the present moment is distinct from spiritual experiences, acceptance of existential issues, or intuitive qualities. Therefore, the lack of correlation between mindfulness and self-transcendence can answer an objection raised by Harrington and Pickles (2009); they believe that mindfulness has a spiritual purpose, and aims to help people to detach from themselves and from the world. However, the results of the present study indicate that mindfulness is distinct from spiritual and intuitive experiences relating to beauty, truth and goodness.

According to the results, mindfulness was significantly related to identity styles and identity commitment dimension. Dispositional mindfulness along with temperament traits, and character traits in particular, which are under influence of environmental learnings, predict a significant amount of variance in identity commitment, i.e. a quality related to successful identity achievement. Moreover, the previous findings indicate that two personality factors - openness and responsibility - predict a significant amount of variance in informational identity style and identity commitment (Dollinger, 1995; Berzonsky, 2004), and also, these two factors are strongly correlated with mindfulness, therefore, we expected mindfulness to be significantly correlated with informational identity style and identity commitment, and the study results confirmed this expectation. The results also showed a strong positive correlation between mindfulness and identity commitment.

The high correlation is also reflected in identity styles because normative and informational identity styles, where 
commitment level is high, have positive correlations with mindfulness. But diffuse-avoidant style, which involves low commitment, is negatively correlated with mindfulness. It seems that individuals with a normative identity style are committed to their values and beliefs; as a result, they experience less anxiety, worry and distress. We can argue that the strong relationship between mindfulness and normative identity style may be related to commitment. The negative correlation between mindfulness and diffuse-avoidant identity style may indicate that in diffuseavoidant identity style, low dispositional mindfulness is related to instability in self-concept and inappropriate decision-making strategies, like avoidance, excuse making, anxiety, and low commitment and exploration.

As we used an instrument, which distinctively assesses the temperament and character traits, in this study, we can understand clearly the amount of variance accounted for in identity styles by each one of the biological and psychological factors. As we can see in stepwise regression analysis, self-transcendence, cooperativeness, and novelty seeking along with mindfulness predicting $26 \%$ of the variance of normative identity style. It seems that character dimensions are more capable of predicting identity styles. This finding may have the implication that environmental factors (differences in learning mechanisms) may have a greater impact on identity orientation. Identity commitment and self-directedness had a strong positive correlation. This finding may indicate that commitment to values and beliefs is strongly related to individual differences in self-directedness. Since the individuals with a high self-directedness have qualities like self-sufficiency, self-centrism, responsibility, purposefulness, and self-acceptance, they are more capable of choosing their own goals and values, independently. Moreover, the results showed that diffuse-avoidant identity style has a strong negative correlation to self-directedness. The results of regression analysis also showed that self-directedness, compared to other personality dimensions, predicts a higher amount of the variance of identity commitment. Self-directedness along with selftranscendence, novelty seeking and mindfulness predict $34 \%$ of the variance of identity commitment. These results indicate the importance of personality factors and mindfulness and the necessity of paying attention to these psychological constructs.

This study has some limitations which have to be pointed out. Given that the data were gathered using self-report instruments, they are vulnerable to the biases related to such measures. In addition, the sample of this study consisted of university students; therefore, we must be cautious in generalizing the results to the entire popula- tion. In the future, researchers can examine mindfulnessbased interventions in people with an identity crisis. It will be also useful to design a longitudinal model to evaluate the effects of mindfulness-based interventions on the successful resolution of identity crisis.

The findings indicate significant relationships between mindfulness and both personality dimensions and identity styles, especially informational identity style and identity commitment. These results may indicate that those who are naturally mindful, and have more adaptive behavior will possibly do better in the process of identity achievement, and during identity crisis. In other words, these qualities can facilitate a successful identity achievement, because a successful identity is characterized by exploration and high commitment. The findings can also imply that mindfulness-based interventions may have positive impacts on the identity crisis, and mindfulness may have a predictive role in the process of identity achievement. Another implication of the finding of the study is that character personality dimensions may have more predictive power than temperament personality dimensions in identity achievement. It also seems that the underlying biological factors of personality have a significant impact on mindfulness and that this finding can be explored further.

\section{Acknowledgments}

This paper is based on a Master's thesis by the first author, which was funded by University of Social Welfare and Rehabilitation Sciences. We would like to thank the Department of Clinical Psychology for its support in this research.

\section{Conflict of Interest}

The authors have no conflicts of interest to declare.

\section{References}

Baer, R. A., Walsh, E., \& Lykins, E. L. (2009). Assessment of mindfulness. In F. Didonna (Ed.), Clinical handbook of mindfulness (pp. 153-168). New York: Springer.

Bao, X., Xue, S., \& Kong, F. (2015). Dispositional mindfulness and perceived stress: The role of emotional intelligence. Personality and Individual Differences, 78, 48-52. doi: 10.1016/j. paid.2015.01.007 
Barnhofer, T., Duggan, D. S., \& Griffith, J. W. (2011). Dispositional mindfulness moderates the relation between neuroticism and depressive symptoms. Personality and Individual Differences, 51(8), 958-62. doi: 10.1016/j.paid.2011.07.032

Berzonsky, M. D. (1990). Self-construction over the life-span: A process perspective on identity formation. Advances in Personal Construct Psychology: A Research Annual, 1, 155-86.

Berzonsky, M. D. (2004). Identity style, parental authority, and identity commitment. Journal of Youth and Adolescence, 33(3), 213-20. doi: 10.1023/b:joyo.0000025320.89778.29

Berzonsky, M. D., \& Ferrari, J. R. (1996). Identity orientation and decisional strategies. Personality and Individual Differences, 20(5), 597-606. doi: 10.1016/0191-8869(96)00001-3

Berzonsky, M. D., \& Kuk, L. S. (2005). Identity style, psychosocial maturity, and academic performance. Personality and Individual Differences, 39(1), 235-47. doi: 10.1016/j.paid.2005.01.010

Blimling, G. (2003). The resident assistant: Applications and strategies for working with college students in residence halls. Dubuque, Iowa: Kendall Hunt.

Brown, K. W., \& Ryan, R. M. (2003). The benefits of being present: Mindfulness and its role in psychological well-being. Journal of Personality and Social Psychology, 84(4), 822-48. doi: 10.1037/0022-3514.84.4.822

Cloninger, C. R., Przybeck, T. R., Svrakic, D. M., \& Wetzel, R. D. (1994). The temperament and Character Inventory (TCI): A guide to its development and use. Missouri: Center for Psychobiology of Personality Washington University.

De Fruyt, F., Van De Wiele, L., \& Van Heeringen, C. (2000). Cloninger's psychobiological model of temperament and character and the five-factor model of personality. Personality and Individual Differences, 29(3), 441-52. doi: 10.1016/s01918869(99)00204-4

Dollinger, S. M. C. (1995). Identity styles and the five-factor model of personality. Journal of Research in Personality, 29(4), 475-9. doi: 10.1006/jrpe.1995.1028

Duriez, B., \& Soenens, B. (2006). Personality, identity styles and authoritarianism: An integrative study among late adolescents. European Journal of Personality, 20(5), 397-417. doi: 10.1002/per.589

Ghorbani, N., Watson, P. J., \& Weathington, B. L. (2009). Mindfulness in Iran and the United States: Cross-cultural structural complexity and parallel relationships with psychological adjustment. Current Psychology, 28(4), 211-24. doi: 10.1007/ s12144-009-9060-3

Giluk, T. L. (2009). Mindfulness, big five personality, and affect: A meta-analysis. Personality and Individual Differences, 47(8), 805-11. doi: 10.1016/j.paid.2009.06.026

Hamill, T. S., Pickett, S. M., Amsbaugh, H. M., \& Aho, K. M. (2015). Mindfulness and acceptance in relation to behavioral inhibition system sensitivity and psychological distress. Personality and Individual Differences, 72, 24-9. doi: 10.1016/j. paid.2014.08.007

Harrington, N., \& Pickles, C. (2009). Mindfulness and cognitive behavioral therapy: Are they compatible concepts. Journal of Cognitive Psychotherapy, 23(4), 315-23. doi: 10.1891/08898391.23.4.315
Kabat Zinn, J. (2003). Mindfulness-based interventions in context: Past, present, and future. Clinical Psychology: Science and Practice, 10(2), 144-56. doi: 10.1093/clipsy/bpg016

Latzman, R. D., \& Masuda, A. (2013). Examining mindfulness and psychological inflexibility within the framework of big five personality. Personality and Individual Differences, 55(2), 129-34. doi: 10.1016/j.paid.2013.02.019

Manfredi, C., Caselli, G., Rovetto, F., Rebecchi, D., Ruggiero, G. M., Sassaroli, S., et al. (2011). Temperament and parental styles as predictors of ruminative brooding and worry. Personality and Individual Differences, 50(2), 186-91. doi: 10.1016/j. paid.2010.09.023

Naseh, M. P., \& Kaviani, H. (2005). Validation of Temperamen and Character Inventory (TCI) in Iranian Sample \& 58 Normative Data. Tehran University Medical Journal, 63(2), 89-98.

Sauer, S., Walach, H., \& Kohls, N. (2011). Gray's behavioural inhibition system as a mediator of mindfulness towards wellbeing. Personality and Individual Differences, 50(4), 506-11. doi: 10.1016/j.paid.2010.11.019

Takeuchi, M., Miyaoka, H., Tomoda, A., Suzuki, M., Lu, X., \& Kitamura, T. (2011). Validity and reliability of the Japanese version of the temperament and character inventory: A study of university and college students. Comprehensive Psychiatry, 52(1), 109-17. doi: 10.1016/j.comppsych.2010.04.002

Tanner, J. L., Arnett, J. J. \& Furlong, A. (2009). The emergence of 'emerging adulthood. In A. Furlong (Ed.), Handbook of youth and young adulthood: New perspectives and agendas (pp. 39-47). New York: Routledge.

Thompson, B. L., \& Waltz, J. (2007). Everyday mindfulness and mindfulness meditation: Overlapping constructs or not. Personality and Individual Differences, 43(7), 1875-85. doi: 10.1016/j.paid.2007.06.017

Tucker, R. P., O'Keefe, V. M., Cole, A. B., Rhoades Kerswill, S. Hollingsworth, D. W., Helle, A. C., et al. (2014). Mindfulness tempers the impact of personality on suicidal ideation. Personality and Individual Differences, 68, 229-33. doi: 10.1016/j. paid.2014.05.001

Vaziri, S., Kashani, F. L., Jamshidifar, Z., \& Vaziri, Y. (2014). Brief report: The identity style Inventory: Validation in Iranian college students. Procedia - Social and Behavioral Sciences, 128, 316-20. doi: 10.1016/j.sbspro.2014.03.163

Verni, K. (2007). The potential impact of mindfulness meditation practices on identity development and psychological stability for adolescents. New Jersey Psychologist, 57(1), 24-7.

Walach, H., Buchheld, N., Buttenmüller, V., Kleinknecht, N., \& Schmidt, S. (2006). Measuring mindfulness - the Freiburg Mindfulness Inventory (FMI). Personality and Individual Differences, 40(8), 1543-555. doi: 10.1016/j.paid.2005.11.025 